\title{
Dedicated time for deliberate practice: one emergency medicine program's approach to point-of-care ultrasound (PoCUS) training
}

\author{
Melissa Hayward, MD, RDMS*; Teresa Chan, BEd, MD*; Andrew Healey, MD*
}

\begin{abstract}
Point-of-care ultrasound (PoCUS) has become an essential skill in the practice of emergency medicine (EM). Various EM residency programs now require competency in basic PoCUS applications. The education literature suggests that deliberate practice is necessary for skill acquisition and mastery. We used an educational theory, Ericsson's model of deliberate practice, to create a PoCUS curriculum for our Royal College of Physicians and Surgeons of Canada EM residency.

Although international recommendations around curriculum requirements exist, this will be one of the first papers to describe the implementation of a specific PoCUS training program. This paper details the features of the program and lessons learned during its initial 3 years. Sharing this experience may serve as a nidus for scholarly discussion around how to best approach medical education in this area.
\end{abstract}

\section{RÉSUMÉ}

L'échographie au point de service (EPS) est devenue une habileté essentielle dans la pratique de la médecine d'urgence (MU). Divers programmes de résidence en $\mathrm{MU}$ exigent maintenant l'acquisition de compétences dans des applications de base de I'EPS. D'après la documentation en éducation, la pratique intentionnelle serait nécessaire à l'acquisition et à la maîtrise de compétences. Les auteurs ont donc appliqué une théorie de l'éducation, le modèle de pratique intentionnelle d'Ericsson, pour élaborer un programme d'EPS dans le cadre de la résidence en $\mathrm{MU}$ du Collège royal.

Bien qu'il existe des recommandations internationales sur les exigences du programme, le présent article est le premier d'une série portant sur la mise en œuvre d'un programme particulier de formation en EPS. II y sera question surtout des éléments du programme et des leçons tirées au cours des trois premières années de mise en œuvre. Ainsi, l'exposé de l'expérience vécue peut servir de matière à des discussions théoriques sur la meilleure façon d'aborder la formation médicale dans le domaine.

\author{
Keywords: Point-of-care Ultrasound, Education, Deliberate \\ Practice

\section{BACKGROUND}

Recent surveys of Canadian emergency medicine (EM) residency programs have demonstrated heterogeneity amongst point-of-care ultrasound (PoCUS) curricula. $^{1-2}$ The Royal College of Physicians and Surgeons of Canada (RCPSC) EM objectives of training include competency in the following PoCUS applications:

- Facilitation of vascular access

- Presence of intraperitoneal free fluid

- Measurement of abdominal aorta diameter

- Presence of pericardial fluid

- Presence of cardiac motion

- Confirmation of intrauterine gestation ${ }^{3}$

The Canadian Association of Emergency Physicians $(\mathrm{CAEP})^{4}$ and The College of Family Physicians of Canada $(\mathrm{CFPC})^{5}$ also recognize PoCUS as a core EM skill. To date, few papers have reported implementation-level descriptions of PoCUS curricula.

\section{RATIONALE}

Deliberate practice is a dominant educational framework for procedural learning. ${ }^{6} \mathrm{~K}$. Anders Ericsson proposed a model that explains the evolution of procedural learning and performance over time. ${ }^{6}$ Using Ericsson's model, we implemented a competencybased, residency-level, PoCUS curriculum grounded in

From the *Department of Medicine, Division of Emergency Medicine, McMaster University, Hamilton, ON.

Correspondence to: Dr. Melissa Hayward, Rm 254 McMaster Clinic, Hamilton General Hospital, 237 Barton St. East, Hamilton, ON L8L 2X2; Email: Melissa.L.Hayward@gmail.com 
his education theories. Our program facilitates the completion of the RCPSC PoCUS objectives ${ }^{3}$ as a minimum competency, with optional extension to include more advanced applications as per national and international guidelines. ${ }^{4,7-9}$

\section{DESCRIPTION OF THE INNOVATION}

We developed a unique curriculum for PoCUS education in the RCPSC EM residency program at McMaster University, based on Ericsson's model. The stages of this model and how they map to our curriculum are summarized in Table 1 .

In PGY-1 or early PGY-2, residents are introduced to PoCUS through a 1-day basic course with prereadings, interactive lectures, and supervised hands-on practice. Within several weeks of the introductory course, the residents are provided with more deliberate practice during a 9-hour scanning day. They scan more than 50 volunteers under the direct observation of PoCUS-credentialed faculty. We provide an instructor-to-participant ratio of $1: 2$, permitting frequent feedback with immediate integration through subsequent practice. A pelvic mannequin is provided to facilitate practice of transvaginal exams. The residents also participate in a 1-hour interactive case review to encourage their understanding of PoCUS within a clinical context.

Next, residents complete a mandatory PGY-2 core rotation lasting 4 weeks (see Figure 1). Residents are provided with CanMEDS-based rotation objectives, competency assessment tools (e.g., observed structured assessment of technical skills, or OSATs), recommended resources, including selected text and journal readings, and case-based presentations.

\begin{tabular}{|c|c|c|c|}
\hline $\begin{array}{l}\text { Level of } \\
\text { Expertise }\end{array}$ & Features of the Stage & Features of Ericsson's Model & Where it is in our Curriculum? \\
\hline Novice & $\begin{array}{l}\text { - Instruction by teacher } \\
\text { - Applies rules } \\
\text { - Performs procedures } \\
\text { step-by-step }\end{array}$ & $\begin{array}{l}\text { - Well-defined task of mastering specific PoCUS } \\
\text { techniques outside of clinical environment } \\
\text { - Direct observation by experts with effective feedback } \\
\text { - Opportunities for repetition and refinement of } \\
\text { technique in low-stakes, simulated environment }\end{array}$ & $\begin{array}{l}\text { Introductory Course and } \\
\text { Scanning Day } \\
\text { - } 1 \text { day duration } \\
\text { - } \text { In either PGY1 or early PGY2 } \\
\text { (pre-requisite for PGY2 } \\
\text { Mandatory Core Rotation) }\end{array}$ \\
\hline Intermediate & $\begin{array}{l}\text { - Same outcomes but } \\
\text { faster and more efficient }\end{array}$ & $\begin{array}{l}\text { - More practice, with same well-defined task, now } \\
\text { within clinical environment } \\
\text { - Direct observation by experts with effective feedback } \\
\text { from variety of PoCUS-capable mentors } \\
\text { - Opportunities for repetition and refinement of } \\
\text { technique in amply supervised real clinical } \\
\text { environment }\end{array}$ & $\begin{array}{l}\text { PGY2 Mandatory Core Rotation } \\
\text { - } 1 \text { month duration } \\
\text { - Phase 1: Residents acquire } \\
\text { specific scans without direct } \\
\text { patient care responsibilities } \\
\text { - Phase 2: Residents integrate } \\
\text { new PoCUS skills during } \\
\text { clinical shifts for patient care }\end{array}$ \\
\hline Expert & $\begin{array}{l}\text { - Rapid and intuitive for } \\
\text { basic scans }\end{array}$ & $\begin{array}{l}\text { - Direct observation by PoCUS-capable mentors } \\
\text { throughout rest of residency }\end{array}$ & $\begin{array}{l}\text { PGY2-5 Clinical Practice } \\
\text { - Clinical shifts during other } \\
\text { junior and senior Emergency } \\
\text { Department rotations }\end{array}$ \\
\hline $\begin{array}{l}\text { Advanced } \\
\text { Expert* }\end{array}$ & $\begin{array}{l}\text { - Rapid and intuitive } \\
\text { for scans }\end{array}$ & $\begin{array}{l}\text { - Dedicated time to master new, advanced PoCUS } \\
\text { techniques } \\
\text { - Again, observation/mentorship with feedback by } \\
\text { PoCUS experts } \\
\text { - Opportunities for repetition and refinement of } \\
\text { advanced techniques }\end{array}$ & $\begin{array}{l}\text { PGY4 Subspecialty Focus* } \\
\text { - } 6 \text { month duration }\end{array}$ \\
\hline
\end{tabular}




\section{Phase 1: Dedicated Scanning Time \\ - Competency-based: self-scheduled and self-directed by the resident \\ - One-on-one teaching sessions with rotation supervisor and subspecialty residents \\ - Real-time supervision for all scans via direct observation or remote review \\ - Focus on basic scanning modalities and facilitation of vascular access}

\section{Phase 2: Integrated Clinical Ultrasound Shifts}

- Scheduled shifts with staff physicians who integrate POCUS into their practice

Figure 1. PGY-2 mandatory core rotation phases

During the first 2 weeks of the rotation (Phase 1), the resident performs PoCUS examinations on patients in the emergency department with the sole objective of gaining experience in image generation and interpretation, and one-on-one mentorship using direct observation or near-real-time remote scan review. We use an online archiving system (Q-Path Ultrasound Data and Process Management Tool, Telexy Networks Inc., Richmond, BC) to facilitate this process. Prompt review allows continuous feedback that helps flag potential areas of difficulty early on. Alternatively, we can also identify the exceptional resident for whom advanced learning objectives can be offered. In this way, we can create individualized learning plans for each resident.

In the latter 2 weeks of the rotation (Phase 2), the resident performs clinical shifts alongside PoCUScredentialed staff physicians. During this phase, the resident gains experience integrating PoCUS applications into their patient-care workflow.

We emphasize a self-directed approach where the residents are given competency-based objectives to complete within the 4-week period. Residents are required to complete 200 or more PoCUS scans to ensure an adequate level of exposure. When the residents feel confident in a particular modality, they can trigger a competency assessment using our locally derived OSATs.

During an OSAT, a PoCUS-credentialed assessor observes the resident as they perform a clinically relevant exam. A modality-specific checklist is completed to ensure that all major competencies are met (see example at http://teresachan.mededlife.org/wp-content/uploads/ sites/6/2014/04/Aorta-OSAT-Creative-Commons.pdf, available for usage under creative commons license). Immediate feedback is provided. OSATs are used along with observations and feedback from supervising clinicians to inform the end-of-rotation report. If concerns about competency arise, the rotation supervisor mandates further practice of the relevant skills until competency is achieved.

Finally, selected residents who have demonstrated interest and skill are eligible for an intensive 6-month subspecialty period where they train in advanced ultrasound applications, as suggested by the literature. ${ }^{8,9}$

\section{OUTCOMES}

Since implementing our new PoCUS curriculum in 2011, we have had 24 residents progress through the PGY-2 core rotation. Of these, $100 \%$ achieved competency in the basic PoCUS applications, as outlined in the RCPSC. All of these residents performed 200 or more reviewed scans during the 4 weeks and accumulated the requisite scans to qualify for the Canadian Emergency Ultrasound Society (CEUS) independent practitioner exam.

Our old curriculum offered the introductory scanning course only. There was no other formal structure in place to support subsequent progression to competency. In the 3 years prior to this program, the median year to qualify for the CEUS exam was PGY-5, with $33 \%$ of residents unable to accomplish this during their residency training. In contrast, after implementation, every resident $(100 \%)$ who completed the dedicated ultrasound rotation was able to qualify for the CEUS exam in PGY-2.

\section{DISCUSSION}

PoCUS is a procedural skill that we are still learning how to incorporate into educational programming. ${ }^{10}$ The "front-end" loading of deliberate practice early in EM residency is particularly advantageous and provides residents with more efficient routes to achieve PoCUS competency. Our curriculum for PoCUS education is a 
model that could be easily integrated into existing EM residency programs.

\section{SUMMARY}

Integration of modern educational frameworks (Ericsson's Deliberate Practice, ${ }^{6}$ Competency-Based Medical Education ${ }^{8}$ ) can facilitate skill acquisition. After redesigning our PoCUS curriculum around the precepts of deliberate practice, our residents were able to achieve competency in all basic PoCUS applications during their junior years of training.

Acknowledgements: Thank you to the residents, directors, and administrators of the McMaster Emergency Medicine FRCP Residency Program, as well as St. Joseph's Healthcare Hamilton Emergency Department staff, for supporting the development and implementation of our PoCUS curriculum.

Competing interests: None declared.

Potential conflicts of interest: All authors have received teaching stipends for their work at ultrasound learning days for the McMaster Emergency Medicine residents.

\section{REFERENCES}

1. Kim DJ, Theoret J, Liao MM, et al. The current state of ultrasound training in Canadian emergency medicine programs: perspectives from program directors. Acad Emerg Med 2012;19(9):E1073-8.

2. Fischer LM, Woo MY, Lee AC, et al. Emergency medicine point-of-care ultrasonography: a national needs assessment of competencies for general and expert practice. C7EM 2015;17(1):74-88.

3. Royal College Objectives of Training for Emergency Medicine; 2011, p. 8. Available at: http://bit.ly/1kmtoIS (accessed 15 March 2014).

4. Hanson A, Healey A, Hebert G, et al. Use of point of care sonography by emergency physicians. C7EM 2012; 14(2):106-12.

5. Canadian College of Family Physicians. Emergency medicine residency objectives, p. 134. Available at: http://www.cfpc.ca/ uploadedFiles/Education/FamilyMed-EMResidencyPrograms (1).pdf (accessed 15 March 2014).

6. Ericsson KA, Krampe RT, Tesch-Römer C. The role of deliberate practice in the acquisition of expert performance. Psychol Rev 1993;100(3):363.

7. Canadian Emergency Ultrasound Society. Recommended standards. Available at: http://ceus.ca/002-standards/002-00. standards.htm (accessed 13 July 2014).

8. Lewiss RE, Pearl M, Nomura JT, et al. CORD-AEUS: consensus document for the Emergency Ultrasound Milestone Project. Acad Emerg Med 2013;20(7):740-5.

9. Atkinson P, Bowra J, Jarman B, et al. International Federation for Emergency Medicine Point-of-care Ultrasound Curriculum Guidelines; 2014. Available at: http:// www.ifem.cc/Resources/PoliciesandGuidelines.aspx (accessed 8 July 2014).

10. Solomon SD, Salfana F. Point-of-care ultrasound in medical education-stop listening and look. $N$ Engl 7 Med 2014; 370(12):1083-5. 